\title{
Tochnical Noto
}

\section{Selection of Dilatation Hardware for PTCA-1985}

\author{
Eric J. Topol, MD, Richard K. Myler, MD, and Simon H. Stertzer, MD
}

\begin{abstract}
Selection of the proper dilatation hardware in performing coronary angioplasty will facilitate the procedure, minimize its cost, and enhance its safety. Over the past 3 years, there has been an acceleration of growth in PTCA catheter and wire technology. We evaluated all currently approved dilatation systems as well as some investigational equipment and herein discuss their relative merits and disadvantages. To aid in operator selection of equipment, the concept of a risk:benefit ratio of potential for intimal trauma vs maximal back-up support is introduced. This information combined with objective data may be helpful in choosing the optimal dilatation equipment, which must be highly individualized for operator preferences and for each patient and his respective coronary anatomy.
\end{abstract}

Key words: coronary angioplasty, dilatation equipment

\section{INTRODUCTION}

Since the introduction of coronary angioplasty by Gruntzig et al [1], advancement in dilatation equipment technology has been the key determinant of overall success and safety [2]. With the development of an independent wire and dilatation catheter system by Simpson and coworkers [3], the primary success rate increased from $65 \%$ [4] to $90 \%$ at the San Francisco Heart Institute, and this experience is paralleled at many centers. The major advance in the field since then has been the availability of low-profile dilatation catheters. With refinement of the tips of these catheters and reduction of their inner lumen size (in the balloon segment), it has become possible to traverse and dilate the most high-grade, distal, and complex lesions. The purpose of this paper is to review the important features of current dilatation systems and describe some of the prototypic equipment undergoing clinical evaluation.

\section{GUIDING CATHETERS}

Current guiding catheters are composed of three layers. The outer layer consists of either polyurethane (USCI; C.R. Bard, Inc., Schneider, Interventional Medical, and

From the University of Michigan Hospital, Ann Arbor, and the San Francísco Heart Institute, Seton Medical Center, Daly City, California.

Address reprint requests to Dr. Eric J. Topol, S-5438 University Hospital, Cardiac Study Unit, The University of Michigan Hospital, Ann Arbor, MI 48109.

Received April 26, 1985; revision accepted June 24, 1985.

(C) 1985 Alan R. Liss, Inc. 
Angiomedics) or polyethylene (ACS; Advanced Cardiovascular Systems), which provides overall stiffness and memory. The middle layer is a wire matrix, allowing for transmission of torque. An inner teflon lining provides lubricity for the passage of the dilatation catheter.

The key features of guiding catheters are summarized in Table I. Stiffness of the catheter is proportional to its potential support, and the ideal guide catheter has stiffness localized to the shaft where it can do the most good in supporting the system against the aortic wall while the dilatation catheter is advanced. On the other hand, the optimal tip quality is soft. Because the tips of guiding catheters are shorter and non-tapered and have thinner walls than diagnostic catheters, their potential for intimal disruption is significantly higher. This is especially true when the guiding catheter is deeply seated to achieve maximal back-up. When selective or subselective engagement is attempted, a softer tip might decrease this risk.

For most guiding catheters, the tip is in plane with the catheter. Each company does, however, manufacture " $G$ " (for the left anterior descending artery) and " $P$ " (for the left circumflex artery) series left coronary guiding catheters, which have their tips oriented $30^{\circ}$ out of plane anteriorly or posteriorly, respectively. Without using these specific catheters, it is almost always possible to intubate the left anterior descending artery subselectively by advancing a standard left coronary guide with counterclockwise rotation. Similarly, seating in the left circumflex can be accomplished by withdrawing the standard guide slightly with clockwise rotation of the catheter.

Side hole right coronary guiding catheters are available from some companies. These catheters were designed to allow deep intubation of the right coronary artery without the problem of catheter wedging. The trade-off in allowing perfusion of the artery while deeply engaged in the vessel is efflux of contrast to the sinus of Valsalva during proximal injections. Catheter wedging is a common problem, particularly in the right coronary artery. The risks of wedging the guide are transient hypoperfusion and potential for intimal trauma. Along with these adverse effects, there is loss of proximal pressure monitoring and inability to obtain a transstenotic pressure gradient. The benefit of superselective intubation is marked stability and axial support and the enhanced ability to successfully cross a very tight lesion. Careful attention to the position of the guide catheter with withdrawal to or out of the coronary ostia at the appropriate time will tend to minimize the problem of catheter wedging.

TABLE I. Guiding Catheters (8F)*

\begin{tabular}{lllll}
\hline & \multicolumn{4}{c}{ Company } \\
\cline { 2 - 5 } Feature & USCI & ACS & IM & AM $^{\text {a }}$ \\
\hline Internal diameter (inches) & .072 & .071 & .074 & .074 \\
Outer layer & PU & PE & PU & PU \\
Tip softness & + & + & + & ++ \\
Distal marker & - & - & + & - \\
Side holes & + & + & + & - \\
Brachial catheters & + & - & - & - \\
\hline
\end{tabular}

*Abbreviations: USCI, Bard, Inc.; ACS, Advanced Cardiovascular Systems, Inc.; IM, Interventional Medical, Inc.; AM, Angiomedics, Inc.; PU, polyurethane; PE, polyethylene.

${ }^{\text {a}}$ Proposed but not available. 
The other key features of guiding catheters relate to their external and internal diameters. A 9F guiding catheter provides more torqueability and back-up support in addition to enhanced contrast delivery and better proximal pressure monitoring. In contrast, the $8 \mathrm{~F}$ guide allows for subselective engagement, less potential for proximal vessel intimal trauma, and fewer groin complications owing to the smaller arterial puncture. Recently, 8F guiding catheters with a large (up to 0.074 inches) central lumen have been introduced along with increased stiffness in the shaft. These catheters may represent the most attractive alternative; they provide excellent opacification and pressure monitoring, easier passage of the dilatation catheter, an opportunity for deep seating, and less potential for proximal intimal disruption or local puncture site complication. With the added stiffness to these "high-flow" $8 \mathrm{~F}$ guiding catheters, there is minimal loss of axial support compared to the $9 \mathrm{~F}$ series. One manufacturer (Interventional Medical) of the $8 \mathrm{~F}$ catheters incorporates a $1-\mathrm{mm}$ distal tantulum marker near the tip. This can be helpful in keeping track of guide catheter position with respect to the coronary ostia and can be used as a ruler in lesion and distance assessment.

Although the discussion has dealt with characteristics of the femoral approach to coronary angioplasty, brachial guiding catheters and this alternative approach offer unique advantages to the experienced operator. Owing to the flexible, soft tip of the guide catheter and the heightened torque control from the arm, superselective intubation with brachial guide catheters can be accomplished more easily and with less risk of intimal damage. The brachial approach can be especially useful for anatomical variants such as a short left main, highly angulated circumflex, or shepherd's crook right coronary artery. Similarly, it might be the only approach possible to dilate an extremely tight and/or distal lesion requiring extreme power of the dilatation system. Brachial angioplasty offers an exception to the concept of increased power-increased risk (vida infra); better back-up support of the dilatation system can often be achieved with less hazard than with the trans-femoral approach.

For optimal choice of a guiding catheter, its design characteristics must be matched with the particular anatomical considerations. The latter can be determined by review of the diagnostic study and with attention to fit of the catheter and anatomy of the proximal target vessel, lesion(s), and aorta. If the first catheter selected is successful, this will tend to minimize the cost (range \$65-95/catheter) and complication rate related to lessened intraaortic and intracoronary manipulation.

\section{DILATATION CATHETERS}

The two currently approved manufacturers of dilatation catheters in this country are USCI (C.R. Bard, Inc., Billerica, Massachusetts) and ACS (Advanced Cardiovascular System, Mountain View, California). An understanding of the basic differences in dilatation catheter design is essential in selecting the preferred catheter. As is shown in Figure 1, the "concentric" lumen system (ACS) has the balloon and distal catheter lumens arranged concentrically, whereas the "eccentric" lumen design (USCI) has an eccentric balloon lumen separate from the distal catheter lumen. Each arrangement has specific merits and disadvantages. The concentric lumen catheter affords rapid inflation and deflation of the balloon and the potential for a lower profile because it is a more compact arrangement. Advantages of the eccentric lumen design include the heightened ability to measure the transstenotic pressure gradient and inject 

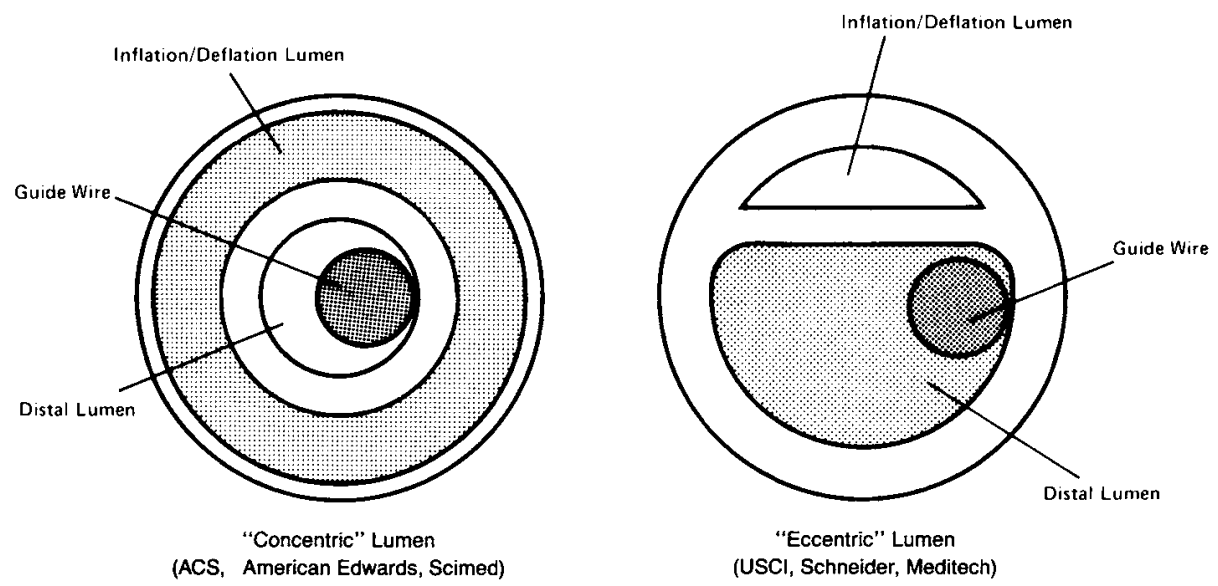

Fig. 1. Cross-sectional representation of dilatation catheters. The concentric lumen catheter is a compact arrangement that allows for rapid balloon inflation and deflation without encroachment of the distal lumen. However, with this design the distal lumen is relatively small, so it is difficult to inject contrast distally and achieve pressure monitoring. The eccentric lumen design features a separate lumen for the balloon and wire. The latter provides an adequate channel for distal dye delivery and pressure monitoring. ACS, Advanced Cardiovascular Systems; USCI, Bard, Inc.

contrast through the distal lumen. Although the ACS catheters theoretically provide distal pressure waveforms and delivery of dye, these are difficult to accomplish without either removing the guide wire or using a smaller wire. Inflation of the balloon in the eccentric design can encroach the distal lumen, which is typically observed as "milking" of contrast from the catheter tip, and result in spurious effects on distal pressure monitoring. However, an injection of flush solution through the wire lumen will reopen sufficient area around the wire to insure adequate pressures. With the concentric lumen design, inflation of the balloon does not significantly affect the caliber of the distal lumen.

Besides the fundamental differences in overall construction, there is a difference in the material of the balloon itself. USCI currently uses polyvinylchloride, whereas ACS employs a polyethylene material. The latter has a lower coefficient of friction (is "softer") so that it has the potential to traverse vascular tortuosity and critical lesions more easily. Another difference in the two catheter types related to balloon material is the heightened ability to overinflate and stretch the balloon of the USCI system, which can increase the balloon size $0.2-0.5 \mathrm{~mm}$ over its prescribed size due to the compliance of polyvinylchloride. This is actually due to the increased compliance of polyvinylchloride compared to polyethylene. A new line of investigational USCI dilatation catheters (known as "LPS plus") with a polyethylene terephthalate (PET) balloon material is undergoing clinical evaluation. This material has the similar advantage of a lower coefficient of friction and has the ability to withstand considerably higher inflation pressures of up to twenty atmospheres without stretching beyond its intended size. The impact of such a balloon might be an enhanced ability to dilate an extremely hard lesion or perhaps to decrease the incidence of restenosis [5].

The feature of a dilatation catheter that receives paramount attention is the balloon profile. Advertised balloon profiles are not standardized with regard to where or how 
the measurements are made. We measured the profile of available dilatation catheters collapsed at midballoon point with calibrated electronic calipers and a dissecting microscope. Our results are summarized in Table II. Of note, the lowest-profile catheter series is the newly released Hartzler LPS. In a sense, this catheter represents a throwback to the original "DG" series of dilatation catheters [1]. The balloon is bonded directly to the wire, but the key advantage compared to the original PTCA catheter is a steerable wire protruding 3 or $10 \mathrm{~mm}$ from the tip of the balloon. The floppy wire cannot be advanced or withdrawn, and the lack of a central lumen precludes distal pressure measurement or distal contrast injections. These disadvantages must be weighed in the context of its extremely low profile $(2.0 \mathrm{~mm}$ balloon: 0.032 inches).

Other important features of the dilatation catheter are the distal taper and shaft stiffness. Due to the radiopaque distal marker in the ACS Simpson-Robert and UltraLow Simpson series catheters, there is less effective tapering compared to USCI. The vent tube in the ACS system enables variability in stiffness of the shaft to be achieved by advancing the tube closer to the balloon.

With all the characteristics of dilatation catheters, it is clear that the choice is difficult and will rely partly on individual operator preference. Although there is tendency to focus on profile, there are several other features that are equally or perhaps more important. Without question, measurement of transstenotic pressure gradients using commercially available equipment is crude and inaccurate compared to high-fidelity micromanometers [6,7]. However, hemodynamic evaluation of the lesion in such a way may be predictive of restenosis [8] and provide immediate ancillary information to support the angiographic result.

Besides considering the type of dilatation catheter, balloon sizing is a necessary part of the selection process. Optimal size can have an effect on long-term outcome [9]. The goal is to dilate the diseased portion of the artery to equal the caliber of the adjacent nondiseased segment. This rule is subject to exception in several situations. With restenosis, underlying spasm, or a proximal saphenous vein graft anastomotic site, oversizing the balloon may be appropriate. Lesions on bends or in patients with diffuse arteriopathy (eg, diabetes mellitus) often require undersizing. Dilatation catheters are expensive ( $\$ 450-500 /$ catheter), so the proper initial choice can not only save the time requisite for an exchange or substitution but also cut down on the equipment cost. Unfortunately, it is often not possible to predict which "tight" lesions will be

TABLE II. Profiles of Available Dilatation Catheters [Collapsed midballoon (inches)]

\begin{tabular}{|c|c|c|c|c|c|}
\hline \multirow[b]{2}{*}{ Catheter } & \multicolumn{5}{|c|}{ Size $(\mathrm{mm})$} \\
\hline & 2.0 & 2.5 & 3.0 & 3.5 & 4.0 \\
\hline \multicolumn{6}{|l|}{ USCI } \\
\hline Low-profile steerable (LPS) & 0.040 & 0.048 & 0.052 & 0.053 & 0.054 \\
\hline \multicolumn{6}{|l|}{ ACS } \\
\hline Simpson-Robert & 0.044 & 0.050 & 0.054 & 0.056 & 0.058 \\
\hline Ultra low-profile & 0.040 & 0.046 & 0.049 & $-^{a}$ & $-^{a}$ \\
\hline Hartzler series & 0.032 & 0.039 & 0.043 & $-{ }^{a}$ & $-^{a}$ \\
\hline \multicolumn{6}{|l|}{ Schneider } \\
\hline Super LPS & 0.041 & 0.050 & 0.053 & $-^{b}$ & $-b$ \\
\hline
\end{tabular}

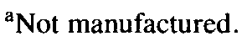

bNot measured. 
amenable to a full-size balloon and which require sequential dilatation. One manufacturer (Schneider) has introduced a three lumen balloon catheter that has both 2.0- and 3.0-mm balloons arranged in series in order to perform sequential dilatation without having to exchange catheters.

\section{GUIDE WIRES}

Wires can be selected on the basis of the following features: steerability, trackability, formability, flexibility, and visibility. The wire that has its core extended to or near the tip (USCI Steerable, ACS Hi-Torque Standard) has maximal steerability and trackability. A "full-body" wire is the easiest to shape, and it allows for maximal torque control and the greatest forward support for the dilatation system, yet it also is the type of wire most likely to render intimal trauma. Although this wire construction is suitable for many lesions, it has particular utility in the dilatation of total occlusion. In this situation, a floppy wire is typically unsuccessful in achieving recanalization.

The remaining available wires have more "flexible" or "floppy" tips, because the core does not extend distally. The flexibility is directly proportional to the distance from the tip of the core to the tip of the wire. Formability is inversely proportional. The basic construction of two of these wires is shown in Figure 2. This class of wires allows for negotiation of tortuosity and acute angles and has the advantage of less potential for lifting a plaque. The trade-off relates to loss of those merits enumerated for a "full-body" wire. Currently available wires are listed in Table III.

Another feature of a wire is the frictional force required to initiate wire movement. This is particularly problematic in a tortuous vessel with the wire bathed in contrast medium. Until recently, USCI wires were only $80 \%$ teflon-coated, and this was a significant difference compared to ACS. Now that the USCI wires are $100 \%$ tefloncoated, there is little appreciable drag of the guide wire in the dilatation system with either product.

Wire size is another parameter that is part of equipment selection. To obtain pressure monitoring and adequate distal contrast injections, a 0.014-inch wire must be used within the USCI low-profile series (LPS) dilatation catheters. However, the USCI 0.016-inch wire or the 0.018-inch Hi-Torque ACS wires can be used in these catheters with compromise of these two functions. Although larger-caliber wires provide maximal forward support for the dilatation system, like "full-body" wires, they also carry the most attendant risk for injuring the intima.

\section{EQUIPMENT UNDER INVESTIGATION}

Guiding catheters manufactured by Angiomedics, Inc., are currently being evaluated. American Edwards and SciMed, Inc., are evaluating a single lumen dilatation catheter and Medi-Tech a double lumen dilatation catheter.

In addition to the PET balloon currently being investigated by USCI, as discussed above, there are a number of innovative catheters that are being designed. Both USCI and ACS are developing a very low profile balloon attached to a wire to be used through a dilatation catheter for tight lesions or total occlusions. ACS has developed and is testing an infusion catheter with sideholes that might be particularly useful in providing adequate coronary blood flow when a vessel has become totally occluded during a procedure, provided a wire can be crossed to the distal vessel [10]. Catheters 
USCI $0.14^{\prime \prime}$ Flexible Steerable Guide Wire

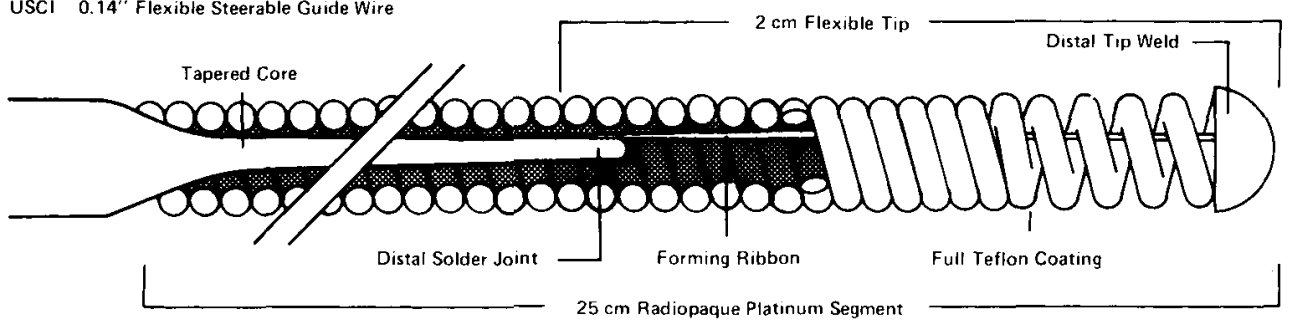

(175 cm Total Length)

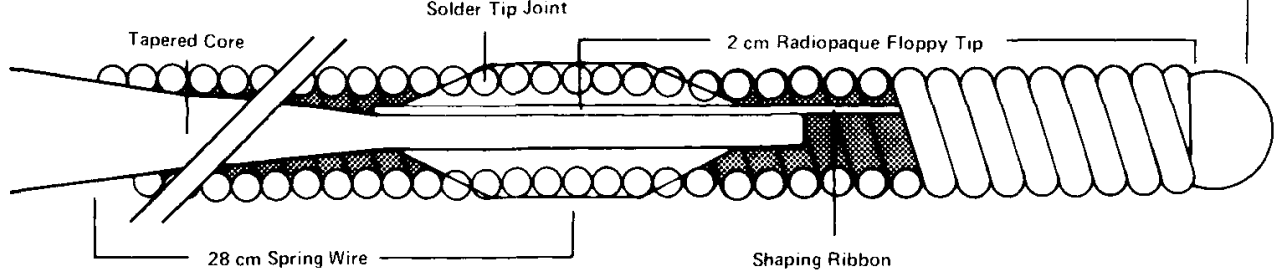

Fig. 2. Schematic representation of two available guide wires. Top, the USCI 0.014-inch flexible wire has no core in the distal $2 \mathrm{~cm}$, and there is a $25-\mathrm{cm}$ distal segment with enhanced radiopacity. Bottom, the ACS 0.014 -inch $\mathrm{Hi}$-Torque floppy wire has less tapering of the core and a shorter distal segment without core. In contrast to the USCI wire, only the distal 2-cm segment has increased radiopacity. Both wires incorporate a forming or shaping ribbon into their design.

TABLE III. Currently Available PTCA Wires

\section{USCI}

0.016-inch Steerable straight, J

0.014 -inch Steerable straight, J

0.014-inch Flexible straight, J

0.014 -inch Very flexible straight, $\mathrm{J}$

0.014 -inch Exchange $(300 \mathrm{~cm})$
ACS

0.018-inch Hi Torque floppy

0.018-inch Hi Torque standard

0.018 -inch Sof-T

0.018 -inch Exchange $(300 \mathrm{~cm})$

0.014-inch Hi Torque floppy

0.014 -inch Hi Torque standard

0.014-inch PDT

0.014-inch Exchange $(300 \mathrm{~cm})$ 


\section{TABLE IV. Risk:Benefit Ratio of PTCA Hardware Selection}

\begin{tabular}{ll}
\hline Less risk of intimal trauma & Increased benefit back-up support \\
\hline No subselective intubation & Subselective intubation \\
$8 \mathrm{~F}$ & 9F guiding catheter \\
Soft tip guide & Stiff guide \\
Flexible or Hi Torque floppy wire & Steerable or Hi Torque standard \\
& wire \\
0.014 -inch Wire & 0.016 -inch or 0.018 -inch Wire \\
\hline
\end{tabular}

that will have a more active role, either with the capacity to drill or achieve actual plaque removal (without laser) are also being assessed.

\section{SUMMARY}

From the above discussion, it is clear that there are a large number of trade-offs and considerations that one must make to select the optimal dilatation system. The basic question that needs to be asked is: Do I want maximal axial support/power or the least risk of intimal trauma? Table IV summarizes the components of the risk: benefit ratio in picking hardware for coronary angioplasty. It is difficult to put together a system with maximal back-up and minimal risk; the objectives often turn out to be contradictory. Beyond these considerations, there are many other features of currently available equipment that provide unique benefits or pose specific disadvantages. A sound selection of hardware based on knowledge of its underlying design and construction together with familiarity will allow for optimal usage, hopefully reducing cost and promoting safety of the procedure.

\section{ACKNOWLEDGMENTS}

The authors thank the following companies for providing technical information and assistance in the preparation of this paper: USCI, ACS, Interventional Medical, and Angiomedics. We are indebted to Mrs. Betty Plunkett for preparation of the manuscript.

\section{REFERENCES}

1. Gruntzig AR, Myler RK, Hanna ES, Turina MI: Transluminal angioplasty of coronary artery stenosis. Circulation 56 [Suppl II]:84, 1977.

2. Gruntzig A. Results from coronary angioplasty and implications for the future. Am Heart J 103:779$783,1982$.

3. Simpson JB, Baim DS, Robert EW, Harrison DC: A new catheter system for coronary angioplasty. Am J Cardio 49:1216-1222, 1982.

4. Stertzer SH, Myler RH, Bruno MS, Walsh E: Transluminal coronary artery dilatation. Practical Cardiol 5:25, 1979.

5. Meier B, Gruentzig AR, King SB III, Douglas JS, Hollman J, Ischinger T, Galan K: Higher balloon dilatation pressure in coronary angioplasty. Am Heart J 107:619-622, 1984.

6. Wijns W, Serruys PW, Brand M, Zeegers E, Kooyman CJ, Reiber JHC: Transstenotic pressure gradients obtained during coronary angioplasty are useful but artifactual measurements (Abstract). Circulation 70 [Suppl II]:II-299, 1984 
7. Sigwart U, Grbic M, Goy J-J, Essinger A: High fidelity pressure gradients across coronary artery stenoses before and after transluminal angioplasty (PTCA) (Abstract). J Am Coll Cardiol 5(2):521, 1985.

8. Marantz T, Williams DO, Reinert S, Gewirtz H, Most AS. Predictors of restenosis after successful coronary angioplasty (Abstract). Circulation 70 [Suppl II]:II-176, 1984.

9. Schmitz HJ, Essen RV, Meyer J, Effert S. The role of balloon size for acute and late angiographic results in coronary angioplasty (Abstract). Circulation 70[Suppl II]:II-295, 1984.

10. Stack RS, Phillips HR. A new infusion catheter for myocardial preservation after failure of coronary angioplasty. Am J Cardiol (in press). 